\title{
Development of a Web-Based Prediction System for Wheat Stripe Rust
}

\author{
Weigang Kuang ${ }^{1}$, Wancai Liu ${ }^{2}$, Zhanhong $\mathrm{Ma}^{1}$, and Haiguang Wang ${ }^{1, *}$ \\ ${ }^{1}$ Department of Plant Pathology, China Agricultural University, Beijing 100193, China \\ ${ }^{2}$ National Agro-Tech Extension and Service Center, Ministry of Agriculture, \\ Beijing 100125, China \\ wanghaiguang@cau.edu.cn
}

\begin{abstract}
A web-based prediction system for wheat stripe rust was developed based on B/S (Browser/Server) mode in this study. Some existing prediction models of wheat stripe rust were collected, analyzed and then stored in SQL Server 2005 database according to certain rules. All these models could be called through this web-based system and used to predict wheat stripe rust. Meanwhile, Using multiple regression analysis principle, prediction regression model could be built based on the input historical data of wheat stripe rust through the network programming via this system, and significance tests of prediction factors could be conducted to obtain optimal prediction model and the built model could be stored into the model database for further prediction of this disease. Using WebGIS technologies, the prediction results of wheat stripe rust could be displayed in different colors in the web map according to the prediction values of disease prevalence. The web-based prediction system for wheat stripe rust developed in this study provided a convenient and fast way for the prediction of wheat stripe rust.
\end{abstract}

Keywords: wheat stripe rust, web-based system, prediction, regression model, WebGIS.

\section{Introduction}

Wheat (Triticum aestivum) with large plating area, is one of the major food crops in China. Pest damage to wheat yield and quality is very serious. Wheat stripe rust (or wheat yellow rust), caused by Puccinia striiiformis f. sp. tritici, is the most important wheat disease in China [1]. It is an important airborne plant disease. Severe epidemics of wheat stripe rust occurred in 1950, 1964, 1990 and 2002 in China and caused server yield losses resulting in significant economic losses [1], [2]. Therefore, timely and accurate prediction of wheat stripe rust has an important significance for taking timely and effective disease control measures and safe production of wheat.

\footnotetext{
* Corresponding author. 
Many methods used to predict wheat stripe rust have been reported, such as regression analysis [3], [4], [5], [6], [7], discrimination analysis [8], [9], [10], Markov forecast method [11], principal component analysis [12], grey model forecast method [13], [14], neural networks [15], [16], [17], [18] and support vector machine [19]. Generally, prediction functions of wheat stripe rust by using these methods were realized on single PC. A few of single computer versions of wheat stripe rust prediction systems have been developed [20], [21], such as PANCRIN that could be used to make simulation experiments on the pandemic of wheat stripe rust in China [21].

WebGIS technology is an emerging technology used in plant protection. It is convenient to process geographic information based on Internet by using WebGIS technology. It plays an important role in pest monitoring and forecasting by making full use of the processing capabilities of geographic information system (GIS) for spatial data and combining GIS with network technologies effectively. Based on longterm study of Sudden Oak Death in California coastal region, Kelly and Tuxen constructed a warning and monitoring website for Sudden Oak Death in California called the "OakMapper" by using WebGIS technology [22]. The information of the website is quarried and browsed in the web map. Users can get the latest information of disease occurrence and learn some knowledge related disease prevention by visiting the website. PhytoPRE+2000, an Internet based version of decision support system for potato late blight was developed for more efficient services in monitoring and management of this disease in Swiss [23]. A potato late blight monitoring and warning system "china-blight" (www.china-blight.net) was constructed based on B/S (Browser/Server) internet structure by combining information technology with the principles of plant disease epidemiology [24]. The system could provide the information on the infection risk of late blight pathogen in different districts of China in the coming 48 hours and also could provide decision support for the chemical control of this disease. With the development of information technologies, the Internet based or WebGIS based plant disease prediction systems play a more and more important role in monitoring and warning of plant diseases.

To the authors' knowledge, there is not any report about web-based wheat stripe rust prediction system. In this study, a prediction system for wheat stripe rust in China was developed using WebGIS technologies. Prediction of wheat stripe rust could be conducted using the existing prediction models or prediction regression models built by using this system based on the input historical data by users. The prediction of this disease by using the information and network technologies was achieved. A convenient and fast way was provided for the prediction of wheat stripe rust and the web-based services also could be provided for integrated control of this disease.

\section{Development Platform of This System}

The web-based prediction system for wheat stripe rust was developed based on the .NET platform. C\# and JavaScript network programming language were used as the system development languages. Internet Information Server (IIS) was used as the web server and ArcGIS Server 9.3 of ESRI Company was used as the map server. The data 
information was stored in SQL Server 2005 database. The Microsoft Visual Studio 2008 was used as the development tool to develop the web-based prediction system for wheat stripe rust.

\section{Overall Structure of This System}

The web-based prediction system for wheat stripe rust was developed based on B/S mode which was a three-layer model structure including web application service layer, logic layer and database layer. The system was composed of the client side and the background (as shown in Fig. 1). Using the historical disease prediction models and the models built by using the system based on the input historical data, the prediction of wheat stripe rust could be implemented and the prediction results could be displayed in different colors in the web map at the client side according to disease prevalence. The background included user management module and model management module that could be used to manage the users and to manage the database, respectively.

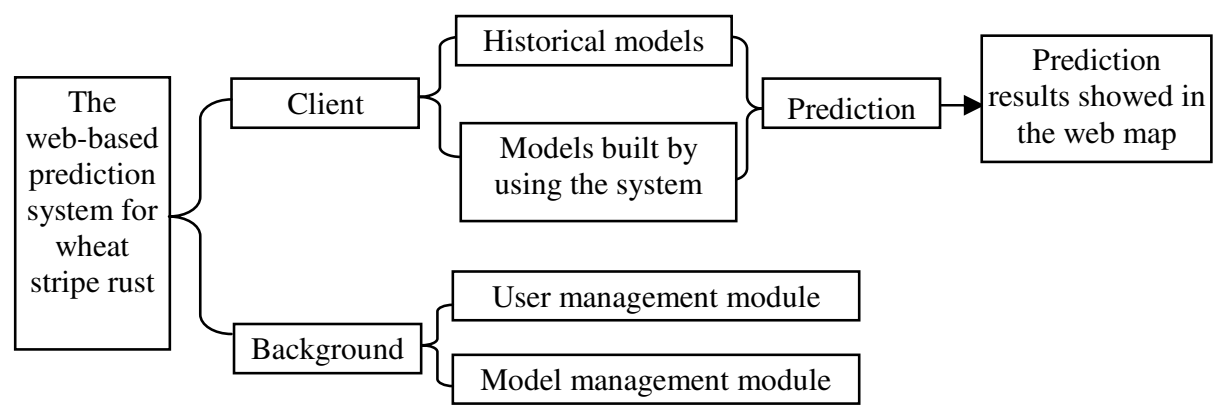

Fig. 1. Overall structure of the web-based prediction system for wheat stripe rust

\section{Function Realization of the Web-Based Prediction System}

The disease prediction function of this web-based system was realized using two methods. One was to realize the function by using the historical models. The existing prediction models were collected and stored in the background database. The models could be queried from the database and then the suitable model could be selected to predict wheat stripe rust. Another method was to realize the prediction function by using the models built based on the input historical data of wheat stripe rust. The function structure chart of the web-based prediction system for wheat stripe rust was shown in Fig. 2. 


\subsection{Building Model Database of Wheat Stripe Rust}

Historical regression prediction models of wheat stripe rust were collected through reviewing relevant literature. The models were stored into model database mainly according to provinces where the disease occurred, counties where the disease occurred, model types, coefficient value of impact factor, the values of constant term of the models, use instructions of the models, and so on. The model database was composed of prediction models and original data table. The models were stored in the model table including the fields, i.e. fid, fdisesse, fprov, fcity, fmodel, fx $1, f \times 2, f \times 3$, $\mathrm{fx} 4$, fx5, fx6, fchang and fexplain (as shown in Table 1). The input historical data of wheat stripe rust used to build regression model was stored in the original data table.

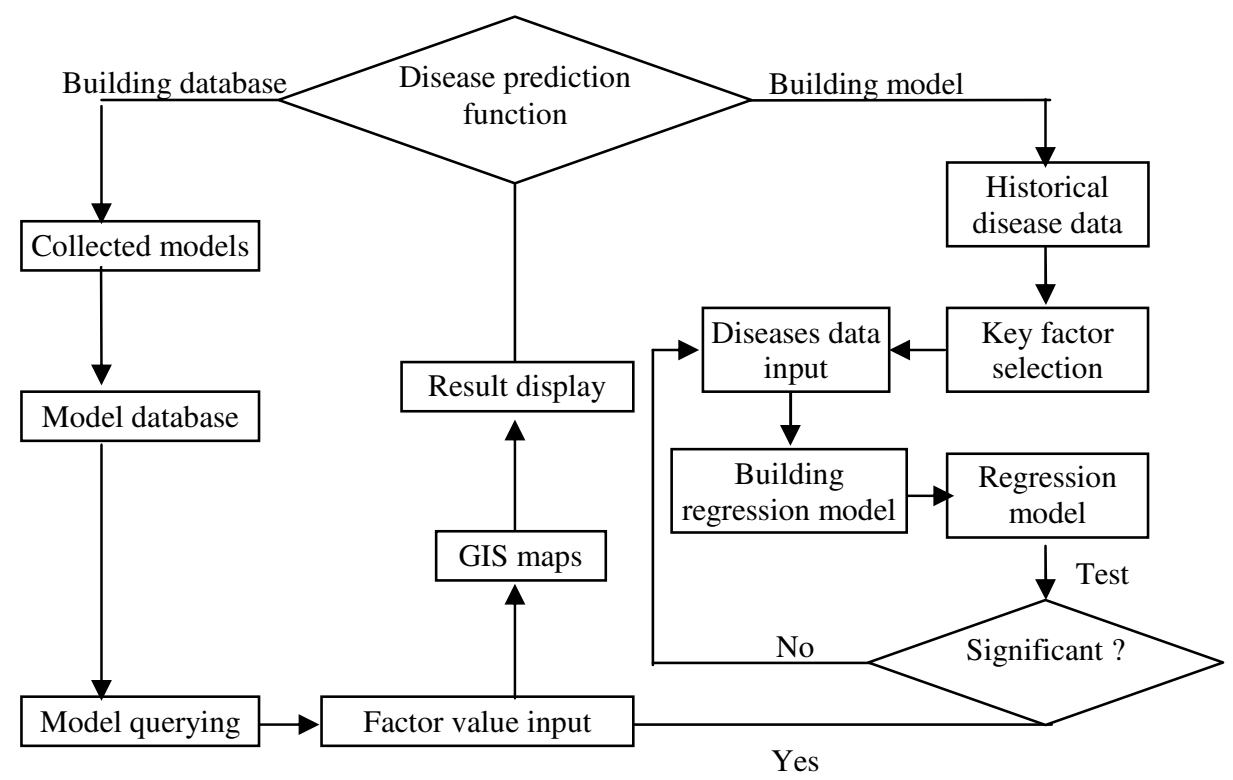

Fig. 2. Function structure chart of the web-based prediction system for wheat stripe rust

Table 1. Disease prediction model table

\begin{tabular}{ccc}
\hline Field name & Data type & Comments \\
fid & int & Disease name \\
fdisesse & nvarchar(50) & Provinces where the disease occurred \\
fprov & nvarchar(50) & counties where the disease occurred \\
fcity & nvarchar(50) & Model type \\
fmodel & nvarchar(50) & The coefficient value of impact factor 1, 2, 3, 4, \\
Fx1, Fx2, Fx3, Fx4, Fx5 and & float & The values of constant term \\
Fx6 & float & Use instructions of the models \\
fchang & text &
\end{tabular}


The regression prediction models of wheat stripe rust that were applied in Ganggu County in Gansu Province, Longnan in Gansu Province, Hanzhong in Shaanxi Province, Shanxi Province and so on, respectively, were collected for the web-based prediction system (as shown in Table 2). Users can query the models of corresponding regions by inputting information at the client side, and then use the corresponding model to carry out the prediction of wheat stripe rust.

Table 2. Some historical prediction model stored in the model database of the web-based prediction system for wheat stripe rust

\begin{tabular}{|c|c|c|c|}
\hline $\begin{array}{l}\text { The suitable } \\
\text { region for } \\
\text { using } \\
\text { prediction } \\
\text { model } \\
\end{array}$ & Prediction model & Variable & Reference \\
\hline $\begin{array}{l}\text { Hanzhong } \\
\text { in Shaanxi } \\
\text { Province }\end{array}$ & $\begin{array}{ll}y=-4.699158 & + \\
0.199445 x_{1} & + \\
0.052963 x_{2} & + \\
0.314299 x_{3}+ & \\
0.014257 x_{4}+ & \\
0.008677 x_{5} & \end{array}$ & $\begin{array}{l}+x_{1} \text { is the amount of pathogen in autumn, } x_{2} \text { is } \\
+\quad \text { the amount of pathogen in spring, } x_{3} \text { is the } \\
+\quad \text { average temperature in April, } x_{4} \text { is the } \\
+\quad \text { precipitation in April, } x_{5} \text { is the proportion of } \\
+\quad \text { susceptible variety area, and } y \text { is disease } \\
\text { prevalence. }\end{array}$ & [5] \\
\hline $\begin{array}{l}\text { Shanxi } \\
\text { Province }\end{array}$ & $\begin{array}{ll}y=-0.2766 & + \\
0.0249 x_{1} & + \\
0.0104 x_{2} & + \\
0.0132 x_{3} & \end{array}$ & $\begin{array}{l}x_{1} \text { is the precipitation in the middle ten days of } \\
+\quad \text { April to the first ten days of May, } x_{2} \text { is the } \\
+\quad \text { precipitation in the middle ten days of May } \\
+\quad \text { and the last tens of May, } x_{3} \text { is the average } \\
\text { relative humidity in May, and } y \text { is disease } \\
\text { prevalence. }\end{array}$ & [6] \\
\hline $\begin{array}{l}\text { Gangu } \\
\text { County in } \\
\text { Gansu } \\
\text { Province }\end{array}$ & $\begin{array}{l}\mathrm{y}=-2.07472+ \\
0.242533 x_{1}+ \\
0.06744 x_{2} \\
0.0091 x_{3}+ \\
0.011865 x_{4}+ \\
0.090152 x_{5}\end{array}$ & $\begin{array}{l}+x_{1} \text { is the average temperature in March, } x_{2} \text { is } \\
\text { the precipitation in March, } x_{3} \text { is the } \\
+\quad \text { precipitation in April, } x_{4} \text { is the precipitation in } \\
+\quad \text { May, } x_{5} \text { is the susceptible variety area, and } y \text { is } \\
\text { disease prevalence. }\end{array}$ & [7] \\
\hline $\begin{array}{l}\text { Nonglan in } \\
\text { Gansu } \\
\text { Province }\end{array}$ & $\begin{array}{l}y=-0.547+ \\
0.025 x_{1}+0.03 x \\
+0.29 x_{3}+0.081 \\
x_{4}\end{array}$ & $\begin{array}{l}x_{1} \text { is the percentage of diseased fields in } \\
+\quad \text { autumn in the preceding year, } x_{2} \text { is the } \\
x_{2} \text { proportion of susceptible variety area, } x_{3} \text { is the } \\
31 \\
\text { average temperature in January in Huixian, } x_{4} \\
\text { is the average maximum temperature in March } \\
\text { in Wudu, and } y \text { is disease prevalence in Spring } \\
\text { in Nonglan. }\end{array}$ & [25] \\
\hline $\begin{array}{l}\text { Jincheng in } \\
\text { Shanxi } \\
\text { Province }\end{array}$ & $\begin{array}{ll}y=3.7644 & + \\
0.0070 x_{1} & \\
0.0097 x_{2} & + \\
0.0273 x_{3} & + \\
0.1079 x_{4} & - \\
0.2145 x_{5} & \end{array}$ & $\begin{aligned} & x_{1} \text { is the precipitation in the last ten-day period } \\
&+ \text { of July in the preceding year, } x_{2} \text { is sunlight in } \\
&- \text { the first ten days of November in the } \\
&+ \text { preceding year, } x_{3} \text { is sunlight in the first ten } \\
&+ \text { days of March in the preceding year, } x_{4} \text { is the } \\
&- \text { average temperature in the middle ten days of } \\
& \text { April, } x_{5} \text { is the precipitation in the last ten-day } \\
& \text { period of April, and } y \text { is disease prevalence. }\end{aligned}$ & [26] \\
\hline $\begin{array}{l}\text { Pingliang in } \\
\text { Gansu } \\
\text { Province }\end{array}$ & $\begin{array}{ll}y=-0.1736 & + \\
0.2051 x_{1} & + \\
0.4345 x_{2} & + \\
0.0089 x_{3} & \end{array}$ & $\begin{array}{l}+x_{1} \text { is disease prevalence in spring, } x_{2} \text { is the } \\
+\quad \text { amount of oversummering pathogen, } x_{3} \text { is the } \\
+\quad \text { total precipitation in September and } \\
\text { October, and } y \text { is disease prevalence on } \\
\text { autumn wheat seedlings. }\end{array}$ & [27] \\
\hline
\end{tabular}




\subsection{Realization of Automatically Modeling Using the System}

The quantity of collected regression prediction model of wheat stripe rust is limited, and most of the models could only be used locally. With the changes in the preconditions, the accuracy of the models should be further improved. Therefore, the model construction module was designed in the web-based prediction system for wheat stripe rust so that the prediction models could be built by using the system. Users can establish regression prediction models using the principle of multiple regression with the help of network programming based on the input historical data of wheat stripe rust. $F$ test on the independent variables at the level of 0.05 or 0.01 could be conducted by using the system to help users to get optimization model.

Regression analysis is a statistical method used to determine the quantitative relationship between two or more variables. Monadic linear regression is to use one of the major factors as independent variable to explain the change of the dependent variable. Multiple regression is to use two or more factors as independent variables to explain the change of the dependent variable. Least square method is used to calculate parameters during regression analysis.

$K$ linear regression using $N$ groups of observations can be solved through the following matrix (as shown in Equation (1)).

$$
\left[\begin{array}{l}
y_{1} \\
y_{2} \\
\cdots \\
y_{n}
\end{array}\right]=\left[\begin{array}{ccccc}
1 & x_{11} & x_{21} & \ldots & x_{k 1} \\
1 & x_{12} & x_{22} & \ldots & x_{k 2} \\
\ldots & \ldots & \ldots & \ldots & \ldots \\
1 & x_{1 n} & x_{2 n} & \ldots & x_{k n}
\end{array}\right]\left[\begin{array}{l}
B_{0} \\
B_{1} \\
\ldots \\
B_{K}
\end{array}\right]+\left[\begin{array}{l}
u_{1} \\
u_{2} \\
\ldots \\
u_{n}
\end{array}\right]
$$

in which, vector $y$ is observation variable vector, matrix $x$ is the matrix of observation variables, vector $B$ is regression parameter vector, vector $u$ is random error vector. The simplified form of Equation (1) could be expressed as Equation (2).

$$
Y=X B+U
$$

According to the principle of least square method, the estimate value of the minimum parameter vector $B$ could be expressed as Equation (3).

$$
B=\left(X^{\prime} X\right)^{-1}\left(X^{\prime} Y\right)
$$

Automatically modeling using the system could be realized in accordance with the following steps. Prediction models of wheat stripe rust could only be built by using regression analysis method via this system. Firstly, the targeted region where disease prediction result would be used should be determined. Secondly, model type should be chosen according to the related data. Five kinds of regression models could be built via this system including binary linear equation, ternary linear equation, first-order linear equation with four independent variables, first-order linear equation with five independent variables, and first-order linear equation with six independent variables. After choosing the proper model and clicking the OK button, a system interface as 
shown in Fig. 3 would be displayed in the client browser. Then the prediction factor values could be input into the system. After inputting all the historical data into the system and clicking the building model button. The system would deal with the data by using regression analysis method. Finally, the prediction model would be built just as shown in Fig. 4.

After building the prediction model by using regression analysis method via the web-based prediction system for wheat stripe rust, $\mathrm{F}$ tests on the independent variables at the level of 0.05 or 0.01 could be conducted to select the model with more accurate by using the system and the optimization model could be obtained. Then the relevant information about the model including the applicable area and the instructions of variables should be input into the system through system interface so that the model could be used in correct way later. The model could be stored into the model database and be used as the same as the historical regression prediction models of wheat stripe rust.

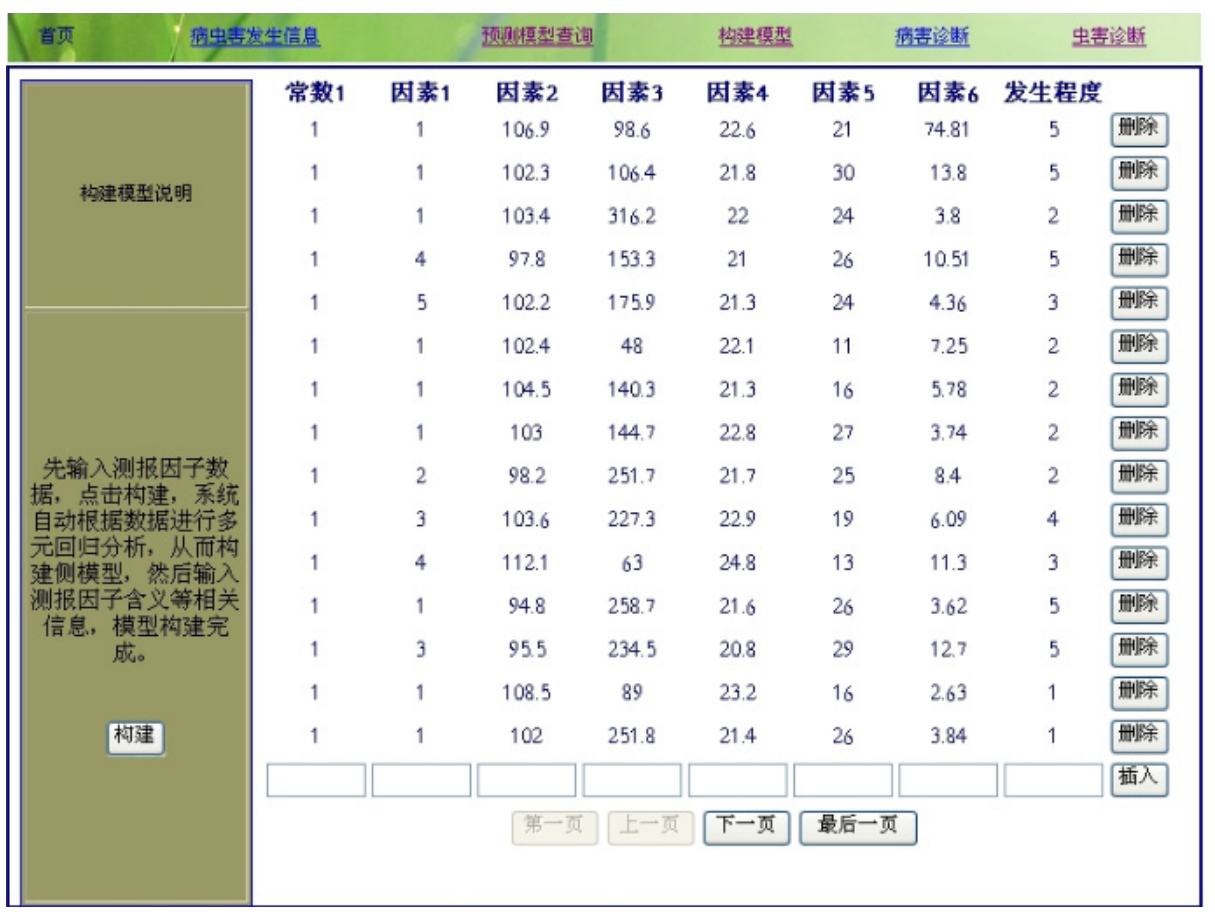

Fig. 3. The system interface for inputting data

\subsection{Realization of Prediction Function Based on WebGIS}

Using the web-based prediction system for wheat stripe rust, the relevant regional prediction model can be queried through the user interface of the system. According to the instruction of the selected model, after the corresponding information being input into the system, the model could be used to predict wheat stripe rust. In order to 


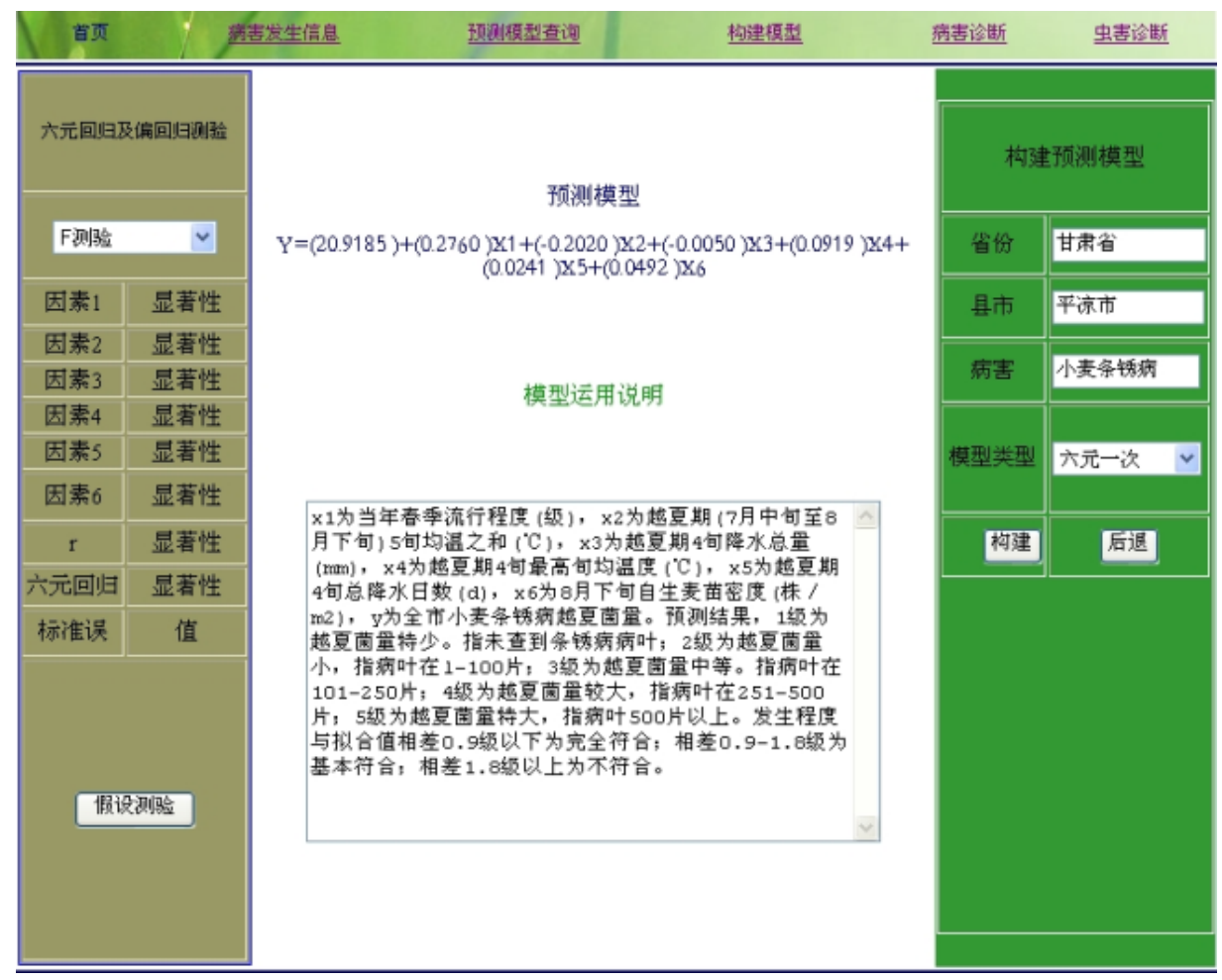

Fig. 4. The prediction model built by using the web-based prediction system for wheat stripe rust

make the prediction results more intuitive, WebGIS technologies were combined with the network technologies in this system and the results could be displayed in different colors in the web map at the client side according to disease prevalence.

Spatial database was established to store national geographic information. The maps used in this system were administrative electronic maps of China which were acquired from the National Geographic Information System in China. The map scale was 1:400000000. The e00 format of the maps was converted to the Shape format by using ArcCatalog software firstly. The ArcGIS 9.3 was used to deal with the vector maps. And the map information was released by using ArcCatalog software.

In the web-based prediction system, the maps were divided into three layers; the first was the county and city boundary layer, the second was the province boundary layer and the third was Chinese boundary layer. Disease prevalence of wheat stripe rust was divided into five classes represented by 1, 2, 3, 4 and 5, respectively. The greater the grade of disease is, the more severe the disease prevalence is. Class 1, 2, 3, 4 and 5 are displayed in green, purple, blue, yellow and red, respectively. This function of the system could be demonstrated by the prediction model of wheat stripe rust in Gangu County that was built by Fan et al. [7]. Firstly the background model 


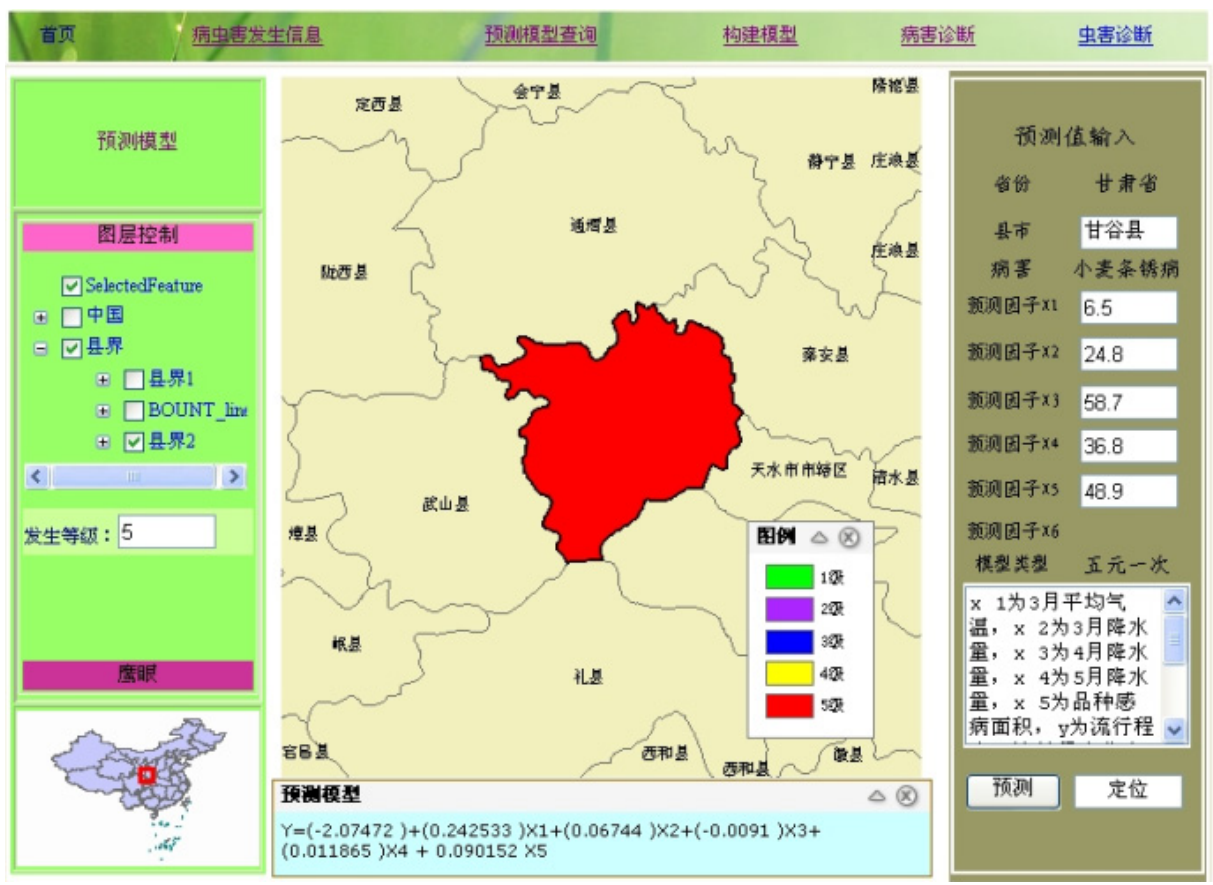

Fig. 5. The prediction results of wheat stripe rust for Gangu County using the web-based prediction system

that was suitable for Gansu County was called in accordance with the rules of the system. Then the model could be used to predict the disease prevalence of wheat stripe rust in Gangu County. The prediction result was shown in Fig. 5.

\section{$5 \quad$ Maintenance of Model Database}

Due to the changes of environments conditions, tillage practices and so on, the accuracies of the prediction models would decrease. In order to improve the model database continually, the prediction model can be added or modified via system background. Thus the validation and verification of the prediction models could be ensured. After inputting the correct user's name and password, the user can enter the system background. The kinds of regression prediction models stored in background were divided into 5 types just like described above. When the user selects the model type that he or she would like to add, the number of variables is determined. Then the user can fill in the form in the system interface with relevant information according to the instruction of the system. In order to ensure that the model could be correctly used later, the variables and using method of the model should be described in the system. After all information is input, the user could click the "Add" button and the model would be stored into the model database. By using the query function, the added models could be selected to predict wheat stripe rust. 


\section{Conclusion and Discussion}

A web-based prediction system for wheat stripe rust was developed using network information technologies in this study. The existing prediction models stored in the model database of the system could be used to predict wheat stripe rust. Moreover, regression models could be built via the system by using C\# network programming technologies based on the principle of multiple regression analysis. The optimized models could be stored into the model database and users could select the suitable model among the database to predict wheat stripe rust in certain region. Thus the waste of information resources and the repeat development of prediction models could be avoided. This system built in this study provided a convenient and fast way for the prediction of wheat stripe rust.

In general, the prediction of wheat stripe rust was conducted on single PC. The web-based prediction of wheat stripe rust could not be carried out before in China. However, the web-based prediction of other plant diseases has been implemented and plays an import role in practical application in China [24]. Based on B/S structure, the system built in this study could display the prediction results in different colors by means of the powerful spatial information processing ability and graphical display function of WebGIS technologies. By combining GIS maps with the prediction models, the system makes the prediction results of wheat stripe rust more intuitive. The prediction of wheat stripe rust could be conducted by using the models built based on the related data via the system and the historical regression prediction models stored in the model database. This web-based prediction could make the prediction of wheat stripe rust more efficient and more convenient and then could provide better services for control decision making.

The development of the web-based prediction system for wheat stripe rust was a meaningful attempt in informationization and automatization of monitoring and early warning on wheat stripe rust. But the functions of spatial analysis and prediction of this system still need further improvement. There are many kinds of methods to construct the prediction models of wheat stripe rust. Each kind of method has its advantages and disadvantages. Only the historical regression prediction models were collected and stored in the model database of this system. And the models that could be built by using this system were also regression models. To make this system more useful, other types of prediction models and other kinds of modeling methods should be added to this system. The prediction results would become more accurate on the basis of complementary advantages of different prediction methods. In order to improve the reliability of results, multiple prediction results using different methods should be showed in overlay format. Thus a scientific basis would be provided for the integrated management of wheat stripe rust.

Acknowledgments. This work was supported in part by National Key Technology R\&D Program (2012BAD19B04) and Special Fund for Agro-scientific Research in the Public Interest (200903004 and 200903035). 


\section{References}

1. Li, Z.Q., Zeng, S.M.: Wheat Rusts in China. China Agriculture Press, Beijing (2002) (in Chinese)

2. Wan, A., Zhao, Z., Chen, X., He, Z., Jin, S., Jia, Q., Yao, G., Yang, J., Wang, B., Li, G., Bi, Y., Yuan, Z.: Wheat Stripe Rust Epidemic and Virulence of Puccinia striiformis f. sp. tritici in China in 2002. Plant Disease 88, 896-904 (2004)

3. Zeng, S.M.: Interregional Spread of Wheat Yellow Rust in China. Acta Phytopathologica Sinica 18, 119-223 (1988) (in Chinese)

4. Yang, Z.W., Shang, H.S., Pei, H.Z., Xie, Y.L.: Dinamic Forecasting of Stripe Rust of Winter Wheat. Scientia Agricultura Sinaca 24, 45-50 (1991) (in Chinese)

5. Hu, X.P., Yang, Z.W., Li, Z.Q., Deng, Z.Y., Ke, C.H.: Studies on the Prediction of Wheat Stripe Rust Epidemics in Hanzhong District of Shaanxi Province. Acta Univ. 28, 18-21 (2000) (in Chinese)

6. Fan, S.Q., Xie, X.S., Li, F., Yin, Q.Y., Zheng, W.Y.: Forecast Model for Prevalent Stripe Rust in Winter Wheat in Shanxi Province. Chinese Journal of Eco-Agriculture 15, 113-115 (2007) (in Chinese)

7. Fan, Z.Y., Cao, S.Q., Luo, H.S., Jin, S.L.: Prediction Model on Wheat Stripe Rust in Gangu Country. Gansu Agriculture Science and Technology 10, 9-21 (2008) (in Chinese)

8. Chen, G., Wang, H.G., Ma, Z.H.: Forecasting Wheat Stripe Rust by Discrimination Analysis. Plant Protection 32, 24-27 (2006) (in Chinese)

9. Chen, G., Wang, H.G., Zhang, L.D., Wang, T., Ma, Z.H.: Preliminary Research on the Regional Relationship of Epidemic of Puccinia striiformis in China. Chinese Agricultural Science Bulletin 22, 415-420 (2006) (in Chinese)

10. Yun, X.W., Wang, H.G., Ma, Z.H.: Forecast of Wheat Stripe Rust by Upper-air Wind. Chinese Agricultural Science Bulletin 23, 358-363 (2007) (in Chinese)

11. Qiang, Z.F.: Markov Forecast of Wheat Stripe Rust in Qinghai in 1998. Plant Protection 25, 19-22 (1999) (in Chinese)

12. Yuan, L., Li, S.Q.: Application of Principal Component Analysis of Wheat Stripe Rust. Computer Engineering and Design 31, 459-461 (2010) (in Chinese)

13. $\mathrm{Pu}, \mathrm{C}$.J.: On Periodic Epidemic Regular Pattern and Prediction of Wheat Stripe Rust in Gansu Province. Acta Phytopathologica Sinica 28, 299-302 (1998) (in Chinese)

14. Liu, R.Y., Ma, Z.H.: The Prediction Methodology of Wheat Stripe Rust Using Combination Model Based on GM (1, 1). Journal of Biomathematics 22, 343-347 (2007) (in Chinese)

15. Hu, X.P., Yang, Z.W., Li, Z.Q., Deng, Z.Y., Ke, C.H.: Prediction of Wheat Stripe Rust in Hanzhong Area by BP Neural Network. Acta Agriculturae Boreali-occidentalis Sinica 9, 28-31 (2000) (in Chinese)

16. Zhang, J.: Research on Chaotic Characteristics of the Disaster Rate of Crops and Its GABPNN Forecasting Model. Jour. of Northwest Sci-Tech Univ. of Agri. and For(Nat. Sci. Ed.). 34, 63-66 (2006) (in Chinese)

17. Jin, N., Huang, W.J., Jing, Y.S., Wang, D.C., Luo, J.H.: Long-term Meteorological Prediction of Country Wide Wheat Stripe Rust by Genetic Neural Network. Chinese Journal of Agrometeorology 30, 243-247 (2009) (in Chinese)

18. Wang, H.G., Ma, Z.: Prediction of Wheat Stripe Rust Based on Neural Networks. In: Li, D., Chen, Y. (eds.) CCTA 2011, Part II. IFIP AICT, vol. 369, pp. 504-515. Springer, Heidelberg (2012) 
19. Wang, H.G., Ma, Z.: Prediction of Wheat Stripe Rust Based on Support Vector Machine. In: Proceedings of 2011 Seventh International Conference on Natural Computation (ICNC 2011), pp. 389-393 (2011)

20. Xiao, C.L., Zeng, S.M.: A Prototype Expert System for Long-term Prediction of Stripe Rust Epidemics. Acta Agriculturae Universitatis Pekinensis 16(suppl.), 126-132 (1990) (in Chinese)

21. Zeng, S.M., Zhang, M.R.: Simulation Experiments on the Pandemic Dynamic of Wheat Stripe Rust in China by Means of a Simulation Model PANCTRIN. Acta Agriculturae Universitatis Pekinensis 16(suppl.), 151-162 (1990) (in Chinese)

22. Kelly, N.M., Tuxen, K.: WebGIS for Monitoring "Sudden Oak Death" in Coastal California. Computers, Environment and Urban Systems 27, 527-547 (2003)

23. Forrer, H.R., Steenblock, T., Fried, P.M.: Monitoring of Potato Late Blight in Switzerland and Development of PhytoPRE+ 2000, an Internet Based Decision Support System. Journal of Agricultural University of Heibei 24, 38-43 (2001)

24. Hu, T.L., Zhang, Y.X., Wang, S.T., Yang, J.Y., Zhang, Y., Cao, K.Q.: Construction and Implementation of China-light: a Monitoring and Warning System on Potato Late Blight in China. Plant Protection 36, 106-111 (2010) (in Chinese)

25. Xiao, Z.Q., Li, Z.M., Fan, M., Zhang, Y., Ma, S.J.: Prediction Model on Stripe Rust Influence Extent of Winter Wheat in Longnan Mountain Area. Chinese Journal of Agrometeorology 28, 350-353 (2007) (in Chinese)

26. Cheng, H.X., Wang, C.M., Shuai, K.J., Li, Y.F., Song, J.F., Wang, J.M.: Meteorological Forecast Models of Wheat Pests in Jincheng City, Shanxi Province. Jiangsu Agricultural Sciences 6, 159-163 (2010) (in Chinese)

27. Liu, X.L.: Study on Prediction Model of Stripe Rust on Autumn Wheat Seedlings in Pingliang, Gansu Province. Gansu Agriculture Science and Technology 10, 37-38 (2010) (in Chinese) 